\title{
Validation of a Traditional Italian-Style Salami Manufacturing Process for Control of Salmonella and Listeria monocytogenes ${ }^{\dagger}$
}

\author{
K. K. NIGHTINGALE, $\ddagger$ H. THIPPAREDDI,§ R. K. PHEBUS,* J. L. MARSDEN, AND A. L. NUTSCH \\ Department of Animal Sciences \& Industry and Food Science Institute, Kansas State University, Manhattan, Kansas 66506, USA
}

MS 05-372: Received 31 July 2005/Accepted 20 November 2005

\begin{abstract}
Italian-style salami batter (formulated with pork shoulder) was inoculated with ca. $7.0 \mathrm{log}$ CFU/g of either Salmonella or Listeria monocytogenes. Salami links (55-mm cellulose casings) were fermented at $30^{\circ} \mathrm{C}$ for 24,40 , or $72 \mathrm{~h}$ and then dried to target moisture/protein ratios (MPRs) of 1.9:1 or 1.4:1. Links were sampled after fermentation $(24,40$, and $72 \mathrm{~h}$ ) and after combined fermentation-drying treatments (MPRs of 1.9:1 and 1.4:1 for all fermentation periods), and microbiological and proximate analyses were performed at each sampling. Pathogen populations were enumerated by direct plating on selective agar and by an injured-cell recovery method. When enumerated by the injured-cell recovery method, Salmonella populations were reduced by 1.2 to $2.1 \log$ CFU/g after fermentation alone ( 24 to $72 \mathrm{~h}$ ) and by 2.4 to $3.4 \log$ CFU/g when fermentation was followed by drying. Drying to an MPR of 1.4:1 was no more effective than drying to an MPR of 1.9:1 $(P>0.05)$. When enumerated directly on selective media, Salmonella populations were reduced from 1.6 to $2.4 \mathrm{log} \mathrm{CFU} / \mathrm{g}$ and from 3.6 to 4.5 $\log \mathrm{CFU} / \mathrm{g}$ for fermentation alone and fermentation followed by drying, respectively. L. monocytogenes populations were reduced by $<1.0 \log \mathrm{CFU} / \mathrm{g}$ following all fermentation and combined fermentation-drying treatments, regardless of the enumeration method. These results suggest that the Italian-style salami manufacturing process evaluated does not adequately reduce high pathogen loads. Processors may thus need to consider supplemental measures, such as raw material specifications and a final heating step, to enhance the lethality of the overall manufacturing process.
\end{abstract}

Foodborne pathogens such as Salmonella and Listeria monocytogenes have been detected in finished dry and semidry fermented sausages, including Italian-style salami, rendering the consumption of these ready-to-eat (RTE) products a potential food safety risk $(20,23)$. In 1999, Mead et al. (22) estimated that $50 \%$ of deaths due to known foodborne pathogens could be attributed to Salmonella or L. monocytogenes infections. Although processors have made significant advances to reduce the prevalence of foodborne pathogens in RTE meat and poultry products, recent prevalence data indicate that 1.4 and $3.3 \%$ of fermented sausages are contaminated with Salmonella and L. monocytogenes, respectively (20). Continued reports of illness outbreaks linked to RTE meat and poultry products-and the numerous variations in processing schedules used in their manufacture-highlight the need for process validation research to further reduce the prevalence of bacterial pathogens that cause human foodborne illnesses.

L. monocytogenes demonstrates high tolerance to environmental stress factors, including low $\mathrm{pH}$ conditions and high salt concentrations (8), and may thus be particularly likely to survive the steps involved in the manufacture of

\footnotetext{
* Author for correspondence. Tel: 785-532-1215; Fax: 785-532-5681; E-mail: phebus@ksu.edu.

$\dagger$ Contribution 05-240-J from the Kansas Agricultural Experiment Station, Manhattan, Kansas.

\$ Present address: Department of Food Science, Cornell University, Ithaca, NY 14853, USA.

$\S$ Present address: Department of Food Science and Technology, University of Nebraska, Lincoln, NE 68583, USA.
}

fermented and dried meat products. L. monocytogenes is not only able to survive and grow under refrigeration conditions, but is also considered a common contaminant and is often difficult to control in food-processing environments $(21,29,30)$. Although $L$. monocytogenes is the most frequent foodborne pathogen isolated from fermented sausages as part of the U.S. Department of Agriculture, Food Safety and Inspection Service (USDA-FSIS) monitoring program for this food product, clinical listeriosis cases have yet to be linked to the consumption of fermented sausages contaminated by L. monocytogenes (31). Traditionally, processors have relied on the intrinsic properties of dry fermented sausages, including low $\mathrm{pH}$ values due to lactic acid production by starter cultures and decreases in water activity, salt, and other antimicrobials (i.e., nitrite and various spices), to suppress the growth of pathogenic microorganisms (23). However, when pathogens such as Salmonella and $L$. monocytogenes are initially present at high levels, these populations may be reduced during the fermentation and drying phases of production but may persist in the final product $(1,11,16,17)$.

Clearly, the presence of Salmonella and L. monocytogenes in finished RTE products is a significant public health concern, and research is necessary to assess the ability of process parameters in the manufacture of Italian-style salami to reduce or eliminate foodborne pathogens from the finished products. In 2001, the USDA-FSIS proposed lethality performance standards for RTE meat products, including a reduction of $6.5 \mathrm{log}$ CFU/g of viable Salmonella populations for finished RTE meats and a reduction of 5.0 
$\log$ CFU/g of Escherichia coli O157:H7 for RTE semidry fermented sausages that contained beef (31). Although no lethality performance standard was proposed for L. monocytogenes in fermented sausages, current U.S. legislation includes a "zero-tolerance" policy for the detection of $L$. monocytogenes in finished RTE foods; thus, RTE products harboring this organism at any detectable level are considered adulterated and are subject to recall (31). Dry and semidry products, such as Italian-style salami, are considered RTE by the USDA-FSIS (31). This study was designed to validate an Italian-style salami manufacturing process to determine the adequacy of its inherent process control measures to reduce Salmonella and L. monocytogenes.

\section{MATERIALS AND METHODS}

Bacterial cultures. Five strains each of $L$. monocytogenes and Salmonella were used in this study. L. monocytogenes strains included ATCC 19116 (serotype 4c) and 19113 (serotype 3), as well as $101 \mathrm{M}, 109$, and $108 \mathrm{M}$ (isolates from raw meat; obtained from Dr. Larry Beuchat, University of Georgia, Griffin). Salmonella strains included Salmonella serotypes Enteritidis (USDAFSIS 15060), Lille (Dr. Larry Beuchat), Montevideo (Dr. Larry Beuchat), Typhimurium (Dr. Stan Bailey, USDA-ARS, Athens, Ga.), and Newport (Centers for Disease Control and Prevention, patient outbreak). Cultures were maintained individually at $4^{\circ} \mathrm{C}$ on tryptic soy agar (TSA; Difco, Becton Dickinson, Sparks, Md.) slants and were biochemically confirmed by API 20 E for Salmonella strains and by API Listeria for L. monocytogenes strains (bioMérieux, Vitek, Inc., Hazelwood, Mo.). Cultures were prepared by performing serial transfers to tryptic soy broth (TSB; Difco, Becton Dickinson) with incubation at $35^{\circ} \mathrm{C}$ for $24 \mathrm{~h}$. Aliquots $(1 \mathrm{ml})$ of each culture were transferred into individual centrifuge bottles containing $100 \mathrm{ml}$ of TSB supplemented with $1 \%$ dextrose and incubated at $35^{\circ} \mathrm{C}$ for $18 \mathrm{~h}$. Cultures were then centrifuged $(15,300 \times g)$ for $10 \mathrm{~min}$ at $4^{\circ} \mathrm{C}($ Beckman $\mathrm{J} 2-21 \mathrm{M} / \mathrm{E}$ centrifuge, JA-14 rotor, Beckman Instruments, Palo Alto, Calif.) and individually washed with $50 \mathrm{ml}$ of $0.1 \%$ peptone diluent (Difco, Becton Dickinson). Cultures were then centrifuged a second time under identical conditions, and the resultant pellet was resuspended in $20 \mathrm{ml}$ of peptone diluent. The five individual strain suspensions were then combined to provide a single mixed inoculum of each pathogen. Salmonella and L. monocytogenes inocula were enumerated (Autoplate 4000, Spiral Biotech, Bethesda, Md.) on xylose lysine desoxycholate (XLD; Difco, Becton Dickinson) and modified Oxford (MOX; Oxoid, Basingstoke, UK) agars, respectively. Plates were incubated at $35^{\circ} \mathrm{C}$ for $24 \mathrm{~h}$.

Italian-style salami batter formulation. The batter formulation as well as the fermentation and drying parameters for the Italian-style salami manufacturing process used in this study were obtained from a meat processor in the United States and are consistent with those used in the manufacture of dry sausages there (34). Salami batter was formulated at the Kansas State University Meat Laboratory, Manhattan. Pork shoulder $(31.8 \mathrm{~kg})$ was ground sequentially through 19-, 13-, and 3.2-mm plates (Hobart model 4732, The Hobart Mfg. Co., Troy, Ohio). A preliminary fat analysis was conducted in triplicate to ensure the desired meat composition of 20\% fat (Hobart Fat Percentage Indicator for Ground Beef model F-101, Hobart Federal Engineering Corp., Minneapolis, Minn.). The meat was then mixed for $1 \mathrm{~min}$ in a ribbon mixer (model HM-100, Hollymatic Corp., Countryside, Ill.). Salami batter ingredients, including $156 \mathrm{ppm}$ of nitrite, $0.83 \%$ dextrose with $0.18 \%$ preformulated spice mixture, starter cultures, and $3.33 \%$ salt, were added in sequence and mixed for 1 min between each ingredient. Starter cultures (Lactacel 444, Micrococcus varians, and Lactacel 75, Pediococcus pentosaceus) were added according to manufacturer specifications (Quest International Flavors \& Ingredients Co., Rochester, Minn.). The batter was allocated to one 13.6-kg batch to serve as an uninoculated control, and two 9.1$\mathrm{kg}$ batches were designated for pathogen inoculation. All three batches of salami batter were stored at $4{ }^{\circ} \mathrm{C}$ until inoculation and stuffing.

Inoculation and stuffing of Italian-style salami. Each batch of salami batter to be inoculated was placed on clean butcher paper and dispersed into a thin rectangular shape with continuously smooth surface topography and approximately 13-mm thickness. The batter was inoculated by pipetting $75 \mathrm{ml}$ of either the Salmonella or L. monocytogenes mixed-strain inoculum onto the meat batter and then manually mixed with gloved hands. The salami batter was stuffed into presoaked collagen casings $(55-\mathrm{mm}$ diameter) with a hydraulic stuffer. Each salami link was formed to ensure that its length was at least twice its diameter. The stuffer was cleaned and sanitized between treatments, and the three batches of stuffed salami links were hung on separate racks for fermentation.

Fermentation and drying of Italian-style salami. Salami links were fermented in a smokehouse (ALKAR, Lodi, Wis.) at $30^{\circ} \mathrm{C}$ dry bulb temperature and $95 \%$ relative humidity $(\mathrm{RH})$ for 24,40 , or $72 \mathrm{~h}$. After fermentation, samples from each treatment were transferred to a drying chamber (Travaglini, Milan, Italy) with a dry bulb temperature of 10 to $13^{\circ} \mathrm{C}$ and 75 to $85 \% \mathrm{RH}$. Samples were dried to target moisture/protein ratios (MPRs) of 1.9:1 and 1.4:1 for each fermentation period. The targeted MPRs used in this study were typical of those used in the manufacture of Italian-style salami in the United States (34). The combined fermentation and drying times required to achieve the target MPRs of 1.9:1 and 1.4:1 were ca. 15 and 20 days, respectively. The environmental conditions of the smokehouse and drying chamber were monitored by a continuous data logging system.

Microbiological sample collection. For each treatment combination, a salami link was aseptically collected and analyzed. Specifically, a sterile, disposable scalpel blade was used to remove the end portions of the link, and a 25 -g sample, including the geometric center of the link, was collected for microbiological analysis. Samples were aseptically blended with $100 \mathrm{ml}$ of peptone diluent for $30 \mathrm{~s}$ with an Oster food processor (Oster, Schaumburg, Ill.) and then transferred to a sterile filter stomacher bag. Each sample was then pummeled for $2 \mathrm{~min}$ in a stomacher (Stomacher 400, Tekmar Co., Cincinnati, Ohio).

Enumeration of Salmonella and L. monocytogenes populations. Salmonella and L. monocytogenes populations were enumerated by direct plating on selective media, as well as by a solid agar repair method to recover injured cells. Samples were serially diluted in peptone diluent and spiral plated onto selective media and onto TSA, which was overlaid with selective media to recover injured cells. Salmonella-inoculated samples were plated on XLD agar and on TSA, which was subsequently overlaid with 10 to 15 $\mathrm{ml}$ of XLD agar (XLD-OVLY) (19). Salami samples inoculated with L. monocytogenes were plated on MOX agar and on TSA, which was subsequently overlaid with 10 to $15 \mathrm{ml}$ of doublestrength MOX agar (MOX-OVLY) (18). TSA plates for injured cell recovery were incubated at $25^{\circ} \mathrm{C}$ for $2 \mathrm{~h}$ prior to being overlaid with selective media. All plates were then incubated at $35^{\circ} \mathrm{C}$ for 24 to $36 \mathrm{~h}$. Presumptive Salmonella and L. monocytogenes colonies were confirmed biochemically. Three colonies per sample 
TABLE 1. Moisture/protein ratio $(M P R)$, water activity $\left(a_{w}\right), p H$, and titratable acidity (TA) of raw batter and Italian-style salami fermented for 24, 40, or $72 \mathrm{~h}$ and subsequently not dried or dried to a target MPR of 1.9:1 or $1.4: 1^{a}$

\begin{tabular}{lcccc}
\hline \multicolumn{1}{c}{ Treatment } & MPR & $\mathrm{a}_{\mathrm{w}}$ & $\mathrm{pH}$ & $\mathrm{TA}(\%)$ \\
\hline Raw batter & & & \\
Fermentation only (not dried) & 3.6 & $\mathrm{NA}$ & 5.6 & 0.31 \\
F24 & 3.6 & & & \\
F40 & 3.4 & 0.952 & 4.4 & 0.93 \\
F72 & 3.2 & 0.947 & 4.3 & 0.93 \\
Dried to MPR 1.9:1 & & & & \\
F24 & 2.0 & 0.935 & 4.4 & 0.94 \\
F40 & 1.9 & 0.929 & 4.5 & 0.93 \\
F72 & 2.0 & 0.929 & 4.5 & 0.93 \\
Dried to MPR 1.4:1 & & & & \\
F24 & & & & \\
F40 & 1.5 & 0.869 & 4.8 & 0.97 \\
F72 & 1.4 & 0.875 & 4.8 & 0.98 \\
\hline
\end{tabular}

$a$ Values are means of three replications. NA, not analyzed; F24, F40, and F72, fermentation times of 24, 40, and $72 \mathrm{~h}$, respectively.

${ }^{b}$ Proximate analysis of raw batter: $23.8 \%$ fat, $54.8 \%$ moisture, $15.0 \%$ protein, and $3.6 \%$ salt.

demonstrating the typical appearance of Salmonella on XLD agar and L. monocytogenes on MOX agar were isolated and confirmed according to USDA-FSIS methodology $(32,33)$. Differences between initial Salmonella and L. monocytogenes populations in salami batter and the subsequent populations present at each sampling period were calculated and reported as reductions of $\log$ CFU per gram.

Proximate and chemical analyses. Proximate analyses were conducted on uninoculated control samples representing raw batter, fermentation, and combined fermentation-drying treatments. Analytical determinations were performed in triplicate according to the procedures of the Association of Official Analytical Chemists. The analyses performed (and the corresponding Association of Official Analytical Chemists procedure numbers) included protein (981.10), titratable acidity (942.15), moisture (934.01), salt (971.19), and $\mathrm{pH}$ (981.12). Water activity was determined with a water activity meter (AQUA LAB model CX-2, Decagon Devices, Inc., Pullman, Wash.).

Experimental design and data analyses. A randomized block experimental design was used to evaluate the ability of the typical Italian-style salami manufacturing process to control $\mathrm{Sal}$ monella and L. monocytogenes in the finished product. Microbiological and proximate analyses were conducted after inoculation, after fermentation for 24,40 , and $72 \mathrm{~h}$, and after combined fermentation-drying treatments (MPRs, 1.9:1 and 1.4:1 for all three fermentation times). Microbial counts were reported as $\log \mathrm{CFU}$ per gram, and log reductions of bacterial populations were calculated. Data from three replications were analyzed by analysis of variance using the General Linear Models procedure of SAS (SAS Institute, Inc., Cary, N.C.); Tukey's studentized range test was used to assess differences in the effect of each treatment on bacterial counts. Analyses were performed separately for Salmonella and L. monocytogenes populations enumerated by direct plating on selective media and by the solid agar repair method.

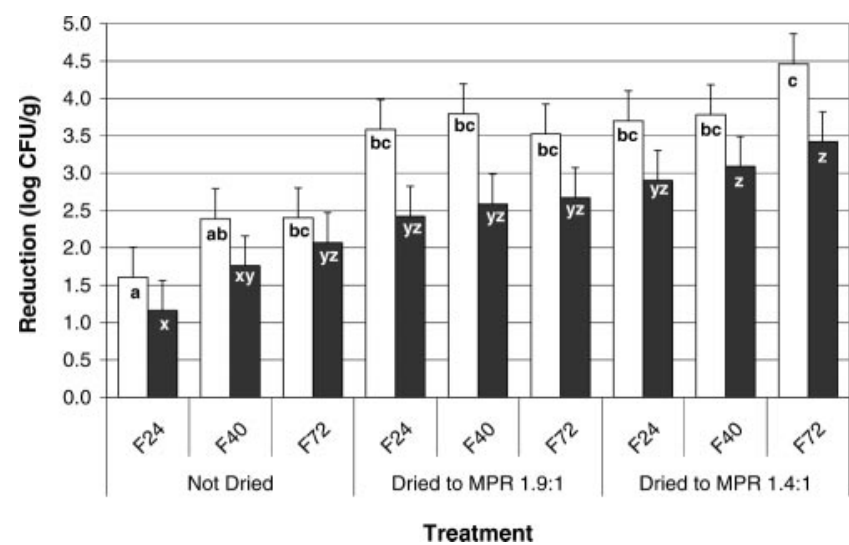

FIGURE 1. Reductions of Salmonella populations in Italian-style salami fermented for 24, 40, or $72 \mathrm{~h}$ (designated by F24, F40, and $F 72$, respectively) and subsequently not dried or dried to moisture/protein ratios of 1.9:1 or 1.4:1. Salmonella populations (initially $7.4 \log C F U / g$ ) were enumerated by $(\square)$ direct plating on selective agar $(X L D)$ and $(\square)$ a solid agar repair method (XLD-OVLY, direct plating on nonselective medium and followed, after $2 \mathrm{~h}$, by an overlay of XLD). Error bars represent the standard deviations of three replications. Within the enumeration method, means lacking common letters are significantly different $(\mathrm{P} \leq 0.05)$.

Comparisons at the $P \leq 0.05$ level were considered statistically significant.

\section{RESULTS AND DISCUSSION}

Proximate and chemical analyses. The desired $\mathrm{pH}$ of 4.5 or less was achieved within the initial $24 \mathrm{~h}$ of fermentation $\left(30^{\circ} \mathrm{C} ; 96 \% \mathrm{RH}\right)$. Extending the fermentation time to 40 and $72 \mathrm{~h}$ resulted in a further reduction of $\mathrm{pH}$ to 4.34 and 4.26, respectively (Table 1 ). A titratable acidity of 0.93 was attained after fermentation for $24 \mathrm{~h}$. Extending the fermentation period beyond $24 \mathrm{~h}$ did not result in further increases in titratable acidity. Fermentation resulted in minimal losses of product moisture, yielding MPRs of 3.6, 3.4, and 3.2 for fermentation times of 24,40 , and $72 \mathrm{~h}$, respectively (Table 1). The target MPRs of 1.9 and 1.4 were attained after drying (Table 1). These finished product attributes are typical of those achieved in the manufacture of Italian-style salami in the United States $(10,34)$.

Impact of the Italian-style salami manufacturing process on Salmonella populations. The fermentation of Italian-style salami for 24 to $72 \mathrm{~h}$ resulted in reductions of 1.6 to $2.4 \log \mathrm{CFU} / \mathrm{g}$ from an initial population level of 7.4 $\log \mathrm{CFU} / \mathrm{g}$ when Salmonella populations were enumerated on XLD agar (Fig. 1). Reductions of Salmonella populations were not different $(P>0.05)$ at 24 versus $40 \mathrm{~h}$ of fermentation; however, fermentation for $72 \mathrm{~h}$ provided a greater reduction than that achieved at $24 \mathrm{~h}(P \leq 0.05)$. Fermentation followed by drying salami to MPRs of 1.9:1 and 1.4:1 resulted in significant $(P \leq 0.05)$ reductions of initial Salmonella populations (Fig. 1). The fermentation of Italian-style salami for $72 \mathrm{~h}$ and then the drying of it to an MPR of 1.4 yielded the greatest reduction of Salmonella populations (XLD-OVLY, $3.4 \log \mathrm{CFU} / \mathrm{g}$; XLD, $4.5 \mathrm{log}$ $\mathrm{CFU} / \mathrm{g}$ ); however, this reduction was not statistically dif- 
ferent $(P>0.05)$ from those achieved by the other combined fermentation-drying treatments (Fig. 1).

Reductions of Salmonella populations during fermentation and drying were ca. 1.0 to $2.0 \log \mathrm{CFU} / \mathrm{g}$ lower $(P$ $\leq 0.05)$ when estimated with a solid repair medium (XLDOVLY) rather than a selective media (Fig. 1). This recovery method has been found to be superior to direct plating on selective media when Salmonella cells are injured because of processing techniques or environmental stresses (19). Our results suggest that a significant population of injured but viable Salmonella was present during the fermentation and drying processes and highlight the importance of using a solid media repair method to accurately validate the ability of RTE meat and poultry manufacturing processes to control Salmonella populations.

Reductions of Salmonella populations observed in this study are consistent with those reported in previous process validation studies for similar meat products. Consistent with our results, previous studies have demonstrated that dry sausage manufacture processes may not be sufficient to achieve the established USDA-FSIS lethality performance standards for Salmonella. Smith et al. (27) reported reductions of 1.8 and $3.5 \mathrm{log}$ CFU/g of Salmonella Dublin and Typhimurium, respectively, from initial levels of $4.75 \mathrm{log}$ $\mathrm{CFU} / \mathrm{g}$ during the manufacture of Lebanon bologna after fermentation for 2 days at $35^{\circ} \mathrm{C}$ and 80 to $85 \% \mathrm{RH}$. After fermentation to $\mathrm{pH}$ values $<4.8$, Ihnot et al. (15) noted a 1.3-log reduction of Salmonella Typhimurium DT104, and an additional 1.6-log reduction was achieved after drying to a final MPR of 1.6:1. Acid adaptation of Salmonella Typhimurium by serial transfers on gradient agar plates acidified with lactic acid before inoculation into Lebanon bologna batter has been shown to result in the better survival of Salmonella populations compared to unadapted wild-type strains (27). Along with these previous studies, our results suggest that Salmonella, particularly acid-adapted cells, is capable of surviving dry and semidry sausage manufacturing processes.

Other studies have demonstrated further reductions of surviving Salmonella populations after fermentation and drying processes by the application of a final thermal processing step or during vacuum-packaged storage of the finished product. Specifically, Ellajosyula et al. (6) reported a reduction of $<2.0 \mathrm{log}$ CFU/g of Salmonella populations present in Lebanon bologna due to a combined fermentation $(\mathrm{pH}<4.7)$ and drying treatment. However, they observed further reductions of Salmonella (>7.0 log CFU/g) when fermentation was followed by final heating treatments at $43.3^{\circ} \mathrm{C}$ for $20 \mathrm{~h}$ or at $48.9^{\circ} \mathrm{C}$ for $3 \mathrm{~h} \mathrm{(6).} \mathrm{Although} \mathrm{Ihnot}$ et al. (15) reported a ca. 3.0-log reduction of Salmonella following fermentation and drying, they noted a 6.0-log reduction of Salmonella following vacuum storage for 56 days at $21^{\circ} \mathrm{C}$. Our results, along with those of previous studies, show that both the fermentation and drying processes in fermented sausage manufacture contribute to initial reductions of Salmonella populations and that this pathogen is further reduced during the natural aging process or by the incorporation of a final heating step.

In the current study, starter cultures were used to en-

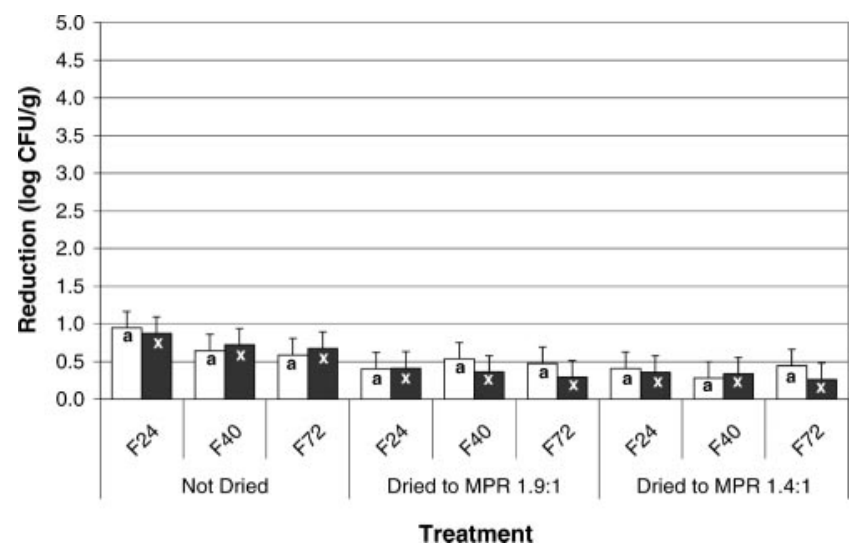

FIGURE 2. Reductions of Listeria monocytogenes populations in Italian-style salami fermented for 24, 40, or $72 \mathrm{~h}$ (designated by $F 24, F 40$, and F72, respectively) and subsequently not dried or dried to moisture/protein ratios of 1.9:1 or 1.4:1. L. monocytogenes populations (initially $7.5 \mathrm{log} C F U / g$ ) were enumerated by ( $\square$ ) direct plating on selective agar (MOX) and ( $\square$ ) a solid agar repair method (MOX-OVLY, direct plating on nonselective medium and followed, after $2 \mathrm{~h}$, by an overlay of MOX). Error bars represent the standard deviations of three replications. Within the enumeration method, means lacking common letters are significantly different $(\mathrm{P} \leq 0.05)$.

sure that an adequate drop in salami $\mathrm{pH}$ was achieved by acid production of lactic acid bacteria. The use of starter cultures compared to natural fermentations provides a greater degree of microbiological safety in fermented meats with respect to consistency in fermentation $(1,12-14)$. Further, starter cultures reduce the $\mathrm{pH}$ of meat batter more quickly than do fermentations that rely on natural meat microflora or "back-slopping." Consistent with the findings of others, our data suggest that, although process controls inherent to the manufacture of Italian-style salami result in significant $(P \leq 0.05)$ reductions when high concentrations of Salmonella (ca. $7.0 \mathrm{log}$ CFU/g) are initially present in raw meat batter, a portion of the pathogen population may remain in the finished product. Results from this study suggest that the process controls of the Italian-style salami manufacture process studied are not sufficient to achieve the proposed lethality performance standard of $6.5 \mathrm{log}$ CFU/g for Salmonella in RTE meats (31). Therefore, processors should consider incorporating a final lethality step that will further reduce the populations of Salmonella to ensure the production of a microbiologically safe RTE product.

Impact of the Italian-style salami manufacturing process on $L$. monocytogenes populations. In contrast to the results observed for Salmonella, similar L. monocytogenes populations $(P>0.05)$ were recovered by direct plating on selective media (MOX) and by the solid agar repair method (MOX-OVLY). None of the fermentation or combined fermentation-drying treatments evaluated significantly $(P>0.05)$ reduced $L$. monocytogenes populations (Fig. 2 ), with all treatments demonstrating reductions of $<1.0 \mathrm{log}$ CFU/g. Furthermore, slight increases $(P>0.05)$ in $L$. monocytogenes populations were observed during the drying period (Fig. 2). 
Although several studies have evaluated the effectiveness of sausage manufacturing processes to control $L$. monocytogenes, results from these studies vary considerably and are likely due to the different process parameters used in each study. Previous studies indicate that some sausage manufacturing processes effectively control L. monocytogenes $(24,26)$ but that other processes allow L. monocytogenes to survive and be detected in the final product if the organism is initially present at high levels $(16,28)$. Previous studies have also reported a slight growth of $L$. monocytogenes during the manufacture of some dry sausages. Campanini et al. (2) reported growth (ca. $1.0 \mathrm{log}$ $\mathrm{CFU} / \mathrm{g}$ ) of L. monocytogenes during the fermentation of Italian salami at $18^{\circ} \mathrm{C}$ and $78 \% \mathrm{RH}$ for 7 days. They also observed that starter cultures stabilized $L$. monocytogenes populations during processing and noted slight additional reductions of L. monocytogenes populations upon further aging (2). Junttila et al. (17) reported a reduction of ca. 1.0 $\log \mathrm{CFU} / \mathrm{g}$ of the initial levels of L. monocytogenes (ca. 3.0 to $5.0 \log \mathrm{CFU} / \mathrm{g}$ ) throughout a 21-day fermentation period during the manufacture of Finnish fermented sausage. Farber et al. (7) reported a slight increase in L. monocytogenes populations during the fermentation and drying of Italianstyle fermented sausages made without starter cultures, whereas populations remained constant during the drying phase and decreased slightly during 4 weeks of storage at $4^{\circ} \mathrm{C}$.

Other researchers (3) demonstrated that fermentation alone to $\mathrm{pH} 4.7$ during the manufacture of Lebanon bologna resulted in a reduction of $2.4 \mathrm{log} \mathrm{CFU} / \mathrm{g}$ of $L$. monocytogenes populations from an initial level of $8.3 \mathrm{log} \mathrm{CFU} / \mathrm{g}$. Johnson et al. (16) observed the survival of L. monocytogenes during the manufacture of hard salami from experimentally infected beef. These authors also reported considerably greater reductions of $L$. monocytogenes populations (reductions of 1.8 and $1.2 \mathrm{log} \mathrm{CFU} / \mathrm{g}$ from initial levels of 3.96 and $4.15 \log \mathrm{CFU} / \mathrm{g}$, respectively) during the fermentation of naturally contaminated and inoculated salami batters, respectively, than were observed in our study. However, the starter cultures, fermentation conditions, and composition of the sausage batter were different from those used in our current study. Despite these differences, Johnson et al. (16) reported the survival of $L$. monocytogenes during the fermentation and drying of salami when initial populations were $\geq 3.0 \log \mathrm{CFU} / \mathrm{g}$. Our findings indicate that $L$. monocytogenes populations may not be adequately reduced by the inherent controls involved in Italian-style salami manufacturing processes if a terminal lethality step is not incorporated.

Similar to Salmonella, L. monocytogenes populations that survive the fermentation and drying processes can be reduced further by the natural aging process or by incorporating an additional lethality measure. Although another study noted a slight growth of $L$. monocytogenes (inoculated at 3.0 to $4.0 \log \mathrm{CFU}$ ) during the fermentation of Norwegian fermented dry sausage, this pathogen was not detected in the finished product after storage for 5.5 months at either 4 or $20^{\circ} \mathrm{C}(24)$. Thevenot et al. (28) reported that decreases in L. monocytogenes populations during the man- ufacture of French sausages were strain dependent and could primarily be attributed to the drying step (28). Differences in the fermentation and drying parameters thus appear to affect the ability of the Italian-style salami manufacturing process to control L. monocytogenes populations. The length of the drying process may be particularly important to control $L$. monocytogenes, and the minimal $L$. monocytogenes reductions observed in the current study may be associated with the shorter drying period compared to the considerably longer drying periods used in previous studies, which reported the absence of $L$. monocytogenes in the finished product $(24,26)$.

Although it is unlikely that salami batter contains initial pathogen levels of $7.0 \mathrm{log} \mathrm{CFU} / \mathrm{g}$, outgrowth in temperature-abusive environments as well as cross-contamination throughout processing may lead to an elevated pathogen load. Although levels of Listeria in raw meats used for the manufacture of fermented sausages are usually lower than $100 \mathrm{CFU} / \mathrm{g}$ (8), researchers have described a high L. monocytogenes contamination rate of $49 \%$ in raw pork sausages (9), indicating the common presence of this pathogen in raw materials used to manufacture RTE meat products. Clearly, a large variation exists with respect to the parameters used in the manufacture of dry sausages. Whereas some processes are adequate to ensure that $L$. monocytogenes is absent in the finished RTE product, others may permit the survival of this pathogen, particularly if it is initially present at high levels. As a result, processors should consider incorporating a final safety measure into their process that would ensure the absence of this pathogen in the finished product. Researchers have shown that the addition of a final heating step is effective to control the presence of $L$. monocytogenes in the final product. Glass and Doyle (11) reported that the incorporation of a final heating step $\left(51.7^{\circ} \mathrm{C}\right.$ for $\left.4 \mathrm{~h}\right)$ in the manufacture of pepperoni yielded a product free of viable L. monocytogenes. Chikthimmah et al. (3) demonstrated that heating Lebanon bologna to $48.9^{\circ} \mathrm{C}$ for $10.5 \mathrm{~h}$ following fermentation to a $\mathrm{pH}$ of 5.0 or 4.7 at $37.7^{\circ} \mathrm{C}$ resulted in a reduction of $>8.0$ $\log \mathrm{CFU} / \mathrm{g}$ of $L$. monocytogenes. Taking into account the stringent zero-tolerance policy for the detection of L. monocytogenes in finished RTE foods, our results suggest that processors who manufacture fermented meats consider evaluating raw meat materials to determine the initial levels of $L$. monocytogenes contamination and thus assess the ability of a validated process to control incoming pathogen loads, as well as consider the incorporation of additional lethality measures to eliminate this pathogen in the finished product.

When exposed to mild environmental stresses such as acid, heat, anaerobiosis, and nutrient starvation, bacterial cells may adapt and become more resistant to subsequent exposures to these adverse conditions through various cellular mechanisms. Previous studies have shown that foodborne pathogens may become acid adapted in foods that contain glucose and that a low storage temperature $\left(10^{\circ} \mathrm{C}\right)$ elicits a greater acid tolerance response (25). The extensive use of organic acid washes in the slaughter industry to reduce microbial loads on carcasses $(4,5)$ achieves moderate 
reductions of foodborne pathogens but may allow the survival of a fraction of the initial populations, essentially making cells that survive the initial exposure to acid more acid resistant during subsequent processes, such as fermentation. A previous study showed that $L$. monocytogenes strains isolated from sausages or the sausage-processing environment were the most resistant to the hurdles used during sausage manufacture (28). In the current study, the adaptation of $L$. monocytogenes populations to acid conditions during growth in a medium containing dextrose may have contributed to the survival of $L$. monocytogenes during fermentation. Further, the drying parameters used in this study $\left(10\right.$ to $\left.13^{\circ} \mathrm{C}\right)$ are within the temperature range known to support the growth of L. monocytogenes (21), although the growth rate may be slow.

Although the Italian-style salami manufacturing process examined in this study reduced Salmonella populations by $3.4 \log \mathrm{CFU} / \mathrm{g}$ (fermentation for $72 \mathrm{~h}$ coupled with drying to a ratio of 1.4:1), the process was relatively ineffective at reducing $L$. monocytogenes populations, with reductions of $\leq 1.0 \mathrm{log}$ observed for all treatments evaluated. Use of a solid agar repair method significantly improved the recovery of Salmonella populations but did not affect the recovery of L. monocytogenes populations. Reductions of Salmonella populations observed in the current study are well below the lethality performance standards for fermented products proposed by the USDA-FSIS. Additionally, finished RTE products contaminated by L. monocytogenes are considered adulterated and are thus subject to recall. Because of the regulations already in place, as well as the proposed standards for fermented meats, our results suggest that additional process controls be incorporated into the current manufacturing processes typical for Italian-style salami to further reduce levels of foodborne pathogens, including Salmonella and L. monocytogenes, to ensure the production of a safe RTE product.

\section{ACKNOWLEDGMENT}

Support was provided by the Cooperative State Research, Extension, and Education Service, USDA, under agreement 93-34211-8362, Food Safety Consortium.

\section{REFERENCES}

1. Berry, E. D., M. B. Liewen, R. W. Mandigo, and R. W. Hutkins. 1990. Inhibition of Listeria monocytogenes by bacteriocin-producing Pediococcus during the manufacture of fermented semidry sausage. J. Food Prot. 53:194-197.

2. Campanini, M., I. Pedrazzoni, S. Barbuti, and P. Baldini. 1993. Behaviour of Listeria monocytogenes during the maturation of naturally and artificially contaminated salami: effect of lactic-acid bacteria starter culture. Int. J. Food Microbiol. 20:169-175.

3. Chikthimmah, N., R. B. Guyer, and S. J. Knabel. 2001. Validation of a $5-\log _{10}$ reduction of Listeria monocytogenes following simulated commercial processing of Lebanon bologna in a model system. $J$. Food Prot. 64:873-876.

4. Cutter, C. N., and G. R. Siragusa. 1994. Efficacy of organic acids against Escherichia coli $\mathrm{O} 157: \mathrm{H7}$ attached to beef carcass tissue using a pilot scale model carcass washer. J. Food Prot. 57:97-103.

5. Dorsa, W. J., C. N. Cutter, and G. R. Siragusa. 1998. Long-term effect of alkaline, organic acid, or hot water washes on the microbial profile of refrigerated beef contaminated with bacterial pathogens after washing. J. Food Prot. 61:158-161.
6. Ellajosyula, K. R., S. Doores, E. W. Mills, R. A. Wilson, R. C. Anatheswaran, and S. J. Knabel. 1998. Destruction of Escherichia coli O157:H7 and Salmonella typhimurium in Lebanon bologna by interaction of fermentation, $\mathrm{pH}$, heating temperature, and time. $\underline{J}$. Food Prot. 61:152-157.

7. Farber, J. M., E. Daley, R. Holley, and W. R. Usborne. 1993. Survival of Listeria monocytogenes during the production of uncooked German, American and Italian-style fermented sausages. Food Microbiol. 10:123-132.

8. Farber, J. M., and P. I. Peterkin. 1991. Listeria monocytogenes, a food-borne pathogen. Microbiol. Rev. 476-511.

9. Farber, J. M., and P. I. Peterkin. 1999. Incidence and behavior of Listeria monocytogenes in meat products, p. 505-564. In E. T. Ryser and E. H. Marth (ed.), Listeria, listeriosis, and food safety, 2nd ed. rev. and expanded. Marcel Decker, Inc., New York.

10. Getty, K. J. K., R. Phebus, J. L. Marsden, D. Y. C. Fung, and C. L. Kastner. 2000. Escherichia coli O157:H7 and fermented sausages: a review. J. Rapid Methods Autom. Microbiol. 8:141-170.

11. Glass, K. A., and M. P. Doyle. 1989. Fate and thermal inactivation of Listeria monocytogenes in beaker sausage and pepperoni. J. Food Prot. 52:226-231

12. Harris, L. J., M. A. Daeschel, M. E. Stiles, and T. R. Klaenhammer 1989. Antimicrobial activity of lactic acid bacteria against Listeria monocytogenes. J. Food Prot. 52:3784-3787.

13. Holley, R. A., A. M. Lammerding, and F. Tittiger. 1988. Microbiological safety of traditional and starter-mediated processes for the manufacture of Italian-style salami. Int. J. Food Microbiol. 7:49-62.

14. Hugas, M., M. Garriga, M. T. Aymerich, and J. M. Monfort. 1995. Inhibition of Listeria monocytogenes in dry fermented sausages by the bacteriocinogenic Lactobacillus sake CT494. J. Appl. Bacteriol. 79:322-330.

15. Ihnot, A. M., A. M. Roering, R. K. Wierzba, N. G. Faith, and J. B. Luchansky. 1998. Behavior of Salmonella typhimurium DT104 during the manufacture and storage of pepperoni. Int. J. Food Microbiol. 40:117-121.

16. Johnson, J. L., M. P. Doyle, R. G. Cassens, and J. L. Shoeni. 1988. Fate of Listeria monocytogenes in tissues of experimentally infected cattle and in hard salami. Appl. Environ. Microbiol. 54:497-501.

17. Junttila, J., J. Hirn, P. Hill, and E. Nurmi. 1989. Effect of different levels of nitrite and nitrate on the survival of Listeria monocytogenes during the manufacture of fermented sausage. J. Food Prot. 52:158161.

18. Kang, D. H., and D. Y. Fung. 1999. Thin agar layer method for recovery of heat-injured Listeria monocytogenes. J. Food Prot. 62: 1346-1349.

19. Kang, D. H., and D. Y. Fung. 2000. Application of thin agar layer method for recovery of injured Salmonella typhimurium. Int. J. Food Microbiol. 10:127-132.

20. Levine, P., B. Rose, S. Green, G. Ransom, and W. Hill. 2001. Pathogen testing of ready-to-eat meat and poultry products collected at federally inspected establishments in the United States 1990 to 1999. J. Food Prot. 64:1188-1193.

21. Lou, Y., and A. E. Yousef. 1999. Characteristics of Listeria monocytogenes important to food processors, p. 131-234. In E. T. Ryser and E. H. Marth (ed.), Listeria, listeriosis, and food safety, 2nd ed. rev. and expanded. Marcel Decker, Inc., New York.

22. Mead, P. S., L. Slutsker, V. Dietz, L. F. McCraig, J. S. Bresee, C. Shapiro, P. M. Griffin, and R. V. Tauxe. 1999. Food-related illness and death in the United States. Emerg. Infect. Dis. 5:607-625.

23. Moore, J. E. 2004. Gastrointestinal outbreaks associated with fermented meats. Meat Sci. 67:565-568.

24. Nissen, H., and A. Holck. 1998. Survival of Escherichia coli O157: H7, Listeria monocytogenes and Salmonella kentucky in Norwegian fermented, dry sausage. Food Microbiol. 15:273-279.

25. Samelis, J., J. S. Ikeda, and J. N. Sofos. 2003. Evaluation of the pHdependent, stationary-phase acid tolerance in Listeria monocytogenes and Salmonella Typhimurium DT104 induced by culturing in media with $1 \%$ glucose: a comparative study with Escherichia coli O157:H7. J. Appl. Microbiol. 95:563-575.

26. Samelis, J., and J. Metaxopoulos. 1999. Incidence and principal 
sources of Listeria spp. and Listeria monocytogenes contamination in processed meats and a meat processing plant. Food Microbiol. 16:465-477.

27. Smith, J. L., S. A. Palumbo, J. C. Kissinger, and C. N. Huhtanen. 1975. Survival of Salmonella dublin and Salmonella typhimurium in Lebanon bologna. J. Milk Food Technol. 38(3):150-154.

28. Thevenot, D., M. L. Delignette-Muller, S. Christieans, and C. Vernozy-Rozand. 2005. Fate of Listeria monocytogenes in experimentally contaminated French sausages. Int. J. Food Microbiol. 101: 189-200.

29. Tompkin, R. B. 2002. Control of Listeria monocytogenes in the foodprocessing environment. J. Food Prot. 65:709-725.

30. Tompkin, R. B., V. N. Scott, D. T. Bernard, W. H. Sveum, and K. S. Gombas. 1999. Guidelines to prevent post-processing contamination from Listeria monocytogenes. Dairy Food Environ. Sanit. 19: $551-562$.
31. U.S. Department of Agriculture, Food Safety and Inspection Service. 2001. Performance standards for the production of processed meat and poultry products; proposed rule. Fed. Regist. 66:12590-12636.

32. U.S. Department of Agriculture, Food Safety and Inspection Service. 2002. Isolation and identification of Listeria monocytogenes from red meat, poultry, egg and environmental samples. In Microbiology laboratory guidebook. Available at: http://www.fsis.usda.gov/Science/ Microbiological_Lab_Guidebook/index.asp. Accessed 5 July 2005.

33. U.S. Department of Agriculture, Food Safety and Inspection Service. 2004. Isolation and identification of Salmonella from meat, poultry and egg products. In Microbiology laboratory guidebook. Available at: http://www.fsis.usda.gov/Science/Microbiological_Lab_Guidebook/ index.asp. Accessed 5 July 2005.

34. U.S. Department of Agriculture, Food Safety and Inspection Service. 2005. Processing procedures: dried meats. Available at: http:// www.fsis.usda.gov/PDF/FSRE_SS_6DriedMeatsProcessing.pdf. Accessed 3 November 2005. 